UDC 519.872:519.217

PACS 07.05.Tp, 02.60.Pn, 02.70.Bf

DOI: $10.22363 / 2658-4670-2020-28-4-319-326$

\title{
Stochastic analysis of a single server unreliable queue with balking and general retrial time
}

\author{
Mohamed Boualem \\ Research Unit LaMOS (Modeling and Optimization of Systems) \\ Faculty of Technology, University of Bejaia, Algeria
}

(received: June 8, 2020; accepted: November 12, 2020)

In this investigation, we consider an $M / G / 1$ queue with general retrial times allowing balking and server subject to breakdowns and repairs. In addition, the customer whose service is interrupted can stay at the server waiting for repair or leave and return while the server is being repaired. The server is not allowed to begin service on other customers until the current customer has completed service, even if current customer is temporarily absent. This model has a potential application in various fields, such as in the cognitive radio network and the manufacturing systems, etc. The methodology is strongly based on the general theory of stochastic orders. Particularly, we derive insensitive bounds for the stationary distribution of the embedded Markov chain of the considered system.

Key words and phrases: Retrial queue, Markov chain, balking, breakdowns and repairs, stochastic orders, bounds, ageing classes

\section{Introduction}

The study on queueing models have become an indispensable area due to its wide applicability in real life situations. Retrial queues occupy an intermediate situation between an Erlang model with loss and classical model with wait, which constitute their limiting models in the case of low and high retrial rates. Retrial queueing systems are characterized by the requirement that customers finding the service area busy must join the retrial group and retry for service at random intervals. Queues in which customers are allowed to retry have been extensively used to model many problems in telephone switching systems, cognitive radio network, manufacturing systems, telecommunication networks and computer systems for competing to gain service from a central processor unit [1]-[3].

Retrial queueing systems with general service times and non-exponential retrial time distributions have been received little attention because of the complexity of the known results. Indeed, in most cases, we are faced with systems of equations whose resolution is complex, or having solutions not 
easily interpretable. For instance, Pollaczek-Khintchine formula requires a numerical inversion of the Laplace transform to compute the distribution of the waiting time. In many cases, even the Laplace transform or probability generating functions are not available in explicit forms. To overcome these difficulties, approximation methods are often used to obtain quantitative and/or qualitative estimates for certain performance measures. For all these reasons, in this study, a particular interest is devoted to the stochastic comparison method based on the general theory of stochastic orders [4], [5].

The stochastic comparison method is a mathematical tool used to study the performance of some systems modeled by continuous or discrete time Markov chains. The general idea of this method is to bound a complex system with a new system that is simpler to solve providing qualitative bounds for these performance measures. These methods represent one of the main research activities in various scientific fields, such as economy, biology, operation research, reliability theory, decision theory, retrial queues and queueing networks [4]-[15].

In the present study, stochastic comparison analysis of an $M / G / 1$ queue with server subject to breakdowns, general service times and non-exponential retrial time distributions by considering the both balking and reneging behavior of the customer is presented.

The rest of the paper is organized as follows. In the next Section, we describe the considered queueing system. In Section 3, we introduce an overview on stochastic orders. In Section 4, we present some lemmas that will be used in what follows. Section 5 focusses on monotonicity properties of the transition operator. Insensitive bounds for the stationary number of customers in the system at a departure epochs are discussed in Section 6.

\section{Mathematical model description}

Primary customers arrive in a Poisson process with rate $\lambda$. If an arriving primary customer finds the server idle, it begins service immediately and leaves the system after service completion. If the server is found to be blocked, the arriving primary customer either enters a retrial queue (according to a FCFS discipline) with probability $p$ or leaves the system with probability $1-p$. The service times follow a general distribution $B(x)$ with corresponding Laplace-Stieltjes transform $B^{\star}(s)$ and the first two moments $\beta_{1}$ and $\beta_{2}$.

The customers in the orbit try to require the service later and the inter retrial times have a general distribution $A(x)$ with corresponding LaplaceStieltjes transform $A^{\star}(s)$. The retrial customer cancels its attempt for service if a primary customer arrives first and either returns to its position in the retrial queue with probability $q$ or quits the system with probability $1-q$.

We assume that the server may fail (or break down), but only when a customer is in service. The time until failure is exponentially distributed with mean $1 / \mu$, but failure of the server can occur only when a customer is being served. When the server fails, the repair starts immediately and the customer just under service waits for the server until repair completion in order to accomplish its remaining service. The repair time is a random variable with probability distribution function $C(x)$, Laplace-Stieltjes transform $C^{\star}(s)$ and the first two moments $\gamma_{1}$ and $\gamma_{2}$. 
Upon failure of the server, the customer in service either remains in the service position with probability $\alpha$ until the server is up or enters a service retrial orbit with probability $1-\alpha$ and keeps returning at times exponentially distributed with mean $1 / \theta$, until the server is repaired. If the customer in service enters the service retrial orbit upon server failure, after repair the server must wait for the customer to return. We refer to this time as the reserved time.

The performance characteristics of our queueing system are available in $\mathrm{Wu}$ et al. [16]. Under the stability condition $p \lambda \beta_{1}\left(1+\mu\left(\frac{1-\alpha}{\theta}+\gamma_{1}\right)\right)<1-q+q A^{\star}(\lambda)$, the one-step transition probabilities are given as:

$$
P_{i j}=\left\{\begin{array}{l}
r_{j}, \quad \text { if } \quad i=0, \quad j \geqslant 0, \\
\left(1-q+q A^{\star}(\lambda)\right) r_{0}, \quad \text { if } \quad i>0, \quad j=i-1, \\
q\left(1-A^{\star}(\lambda)\right) r_{j-1}+\left(1-q+q A^{\star}(\lambda)\right) r_{j-i+1}, \text { if } i>0, j>i-1, \\
0, \quad \text { otherwise, }
\end{array}\right.
$$

where

$$
r_{m}=\int_{0}^{+\infty} \frac{(p \lambda x)^{m}}{m !} \exp \{-p \lambda x\} d B^{\bullet}(x), \quad m=0,1,2, \ldots
$$

is the distribution of the number of primary customers which arrive during the generalized service time of the $(n+1)$ th customer. We define the generalised service time as the length of time from when a customer begins service until service completion (that includes: some eventual repair times $\left(X_{i}\right)$ and reserved times $\left.\left(Y_{i}\right)\right)$ with common distribution

$$
B^{\bullet}(x)=\sum_{i=0}^{\infty} \sum_{j=0}^{i} \int_{0}^{x}\left(\begin{array}{l}
i \\
j
\end{array}\right) \alpha^{j}(1-\alpha)^{i-j} \frac{(\mu y)^{i}}{i !} e^{-\mu y} C_{i, j}^{(2)}(x-y) d B(y) .
$$

\section{Overview on stochastic orders and ageing notions}

Stochastic ordering is useful for studying internal changes of performance due to parameter variations, to compare distinct systems, to approximate a system by a simpler one, and to obtain upper and lower bounds for the main performance measures of systems. For a comprehensive discussion on these stochastic orders, see [4], [5].

Let $X$ and $Y$ be two random variables non-negative with distribution functions $F$ and $G$, respectively.

Laplace order $\left(\leqslant_{L}\right): X \leqslant_{L} Y \Leftrightarrow \int_{0}^{+\infty} e^{-s x} d F(x) \geqslant \int_{0}^{+\infty} e^{-s x} d G(x), \forall s \geqslant 0$.

Stochastic order $\left(\leqslant_{s t}\right): X \leqslant_{s t} Y \stackrel{0}{\Leftrightarrow} F(x) \geqslant G(x), \underset{\infty}{\forall} \in \mathbb{R}$.

Convex order $\left(\leqslant_{v}\right): X \leqslant_{v} Y \Leftrightarrow \int_{x}^{\infty}(1-F(t)) d t \leqslant \int_{x}^{\infty}(1-G(t)) d t, \forall x \geqslant 0$. 
Proposition 1. Let $X$ be a random variable with distribution function $F$ and finite mean $m$.

(a) $F$ is New Better than Used in Expectation (NBUE) iff $F \leqslant_{v} F^{*}$,

(b) $F$ is New Worse than Used in Expectation (NWUE) iff $F^{*} \leqslant \leqslant_{v} F$,

(c) $F$ is of class $\mathcal{L}$ iff $F \geqslant_{L} F^{*}$, where $F^{*}$ is the exponential distribution function with the same mean as $F$.

\section{Comparison bounds for the probability $r_{m}$}

This subsection presents several useful lemmas which will be used later in establishing the main results. For this, we consider two $M / G / 1$ queue with general retrial times allowing balking and server subject to breakdowns and repairs with parameters $\lambda^{(i)}, q^{(i)}, \alpha^{(i)}, \mu^{(i)}, C^{(i)}, B^{(i)}$, for $i=1,2$ respectively.

Lemma 1. If $\lambda^{(1)} \leqslant \lambda^{(2)}, q^{(1)} \leqslant q^{(2)}, \alpha^{(1)} \geqslant \alpha^{(2)}, \mu^{(1)} \leqslant \mu^{(2)}, C^{(1)} \leqslant{ }_{s t} C^{(2)}$, $B^{(1)} \leqslant_{s t} B^{(2)}$, then $\left\{r_{m}^{(1)}\right\} \leqslant_{s t}\left\{r_{m}^{(2)}\right\}$.

Lemma 2. If $\lambda^{(1)} \leqslant \lambda^{(2)}, q^{(1)} \leqslant q^{(2)}, \alpha^{(1)} \geqslant \alpha^{(2)}, \mu^{(1)} \leqslant \mu^{(2)}, C^{(1)} \leqslant{ }_{v} C^{(2)}$, $B^{(1)} \leqslant_{v} B^{(2)}$, then $\left\{r_{m}^{(1)}\right\} \leqslant_{v}\left\{r_{m}^{(2)}\right\}$.

Proof. To show both lemmas, we have to establish the usual numerical inequalities

$$
\begin{gathered}
\bar{r}_{m}^{(1)}=\sum_{n \geqslant m} r_{n}^{(1)} \leqslant \bar{r}_{m}^{(2)} \quad\left(\text { for } \quad \leqslant_{s}=\leqslant_{s t}\right), \\
\bar{r}_{m}^{(1)}=\sum_{n \geqslant m} \bar{r}_{n}^{(1)} \leqslant \bar{r}_{m}^{(2)} \quad\left(\text { for } \leqslant_{s}=\leqslant v\right) .
\end{gathered}
$$

By definition, we have

$$
\begin{gathered}
\bar{r}_{m}^{(i)}=\sum_{j \geqslant m} r_{j}^{(i)}=\int_{0}^{+\infty} \sum_{j \geqslant m} \frac{\left(p^{(i)} \lambda^{(i)} x\right)^{j}}{j !} e^{-p^{(i)} \lambda^{(i)} x} d B^{\bullet^{(i)}}(x), i=1,2 . \\
\overline{\bar{r}}_{m}^{(i)}=\sum_{j \geqslant m} \bar{r}_{j}^{(i)}=\int_{0}^{+\infty} \sum_{j \geqslant m} \sum_{l \geqslant j} \frac{\left(p^{(i)} \lambda^{(i)} x\right)^{l}}{l !} e^{-p^{(i)} \lambda^{(i)} x} d B^{\bullet^{(i)}}(x), i=1,2 .
\end{gathered}
$$

The rest of the proof is known in the more general setting of a random summation.

\section{Monotonicity properties of the transition operator}

Let $\mathbf{T}$ be the transition operator which associates to every distribution $\omega=\left\{\omega_{j}\right\}_{j \geqslant 0}$ a distribution $\mathbf{T} \omega=\left\{\nu_{j}\right\}_{j \geqslant 0}$ such that $\nu_{j}=\sum_{i \geqslant 0} \omega_{i} P_{i j}$.

Theorem 1. The transition operator $\mathbf{T}$ is monotone with respect to the orders stochastic $\left(\leqslant_{s t}\right)$ and convex $\left(\leqslant_{v}\right)$. 
Proof. It is well known that an operator is monotone with respect to $\leqslant_{s t}$ if and only if $\bar{P}_{i j}-\bar{P}_{i-1 j} \geqslant 0$, and is monotone with respect to $\leqslant_{v}$ if and only if $\overline{\bar{P}}_{i-1 j}+\overline{\bar{P}}_{i+1 j}-2 \overline{\bar{P}}_{i j} \geqslant 0, \forall i, j$.

In our case, $\bar{P}_{i j}=\sum_{l=j}^{\infty} P_{i l}$ and $\overline{\bar{P}}_{i j}=\sum_{l=j}^{\infty} \bar{p}_{i l}$.

Now, we consider two $M / G / 1$ queue with general retrial times allowing balking and server subject to breakdowns and repairs with parameters $\lambda^{(i)}$, $q^{(i)}, \alpha^{(i)}, \mu^{(i)}, C^{(i)}, A^{(i)}, B^{(i)}$, for $i=1,2$ respectively. In the following theorem, we give comparability conditions of two transition operators $\mathbf{T}^{1}$ and $\mathbf{T}^{2}$.

Theorem 2. If $\lambda^{(1)} \leqslant \lambda^{(2)}, q^{(1)} \leqslant q^{(2)}, \alpha^{(1)} \geqslant \alpha^{(2)}, \mu^{(1)} \leqslant \mu^{(2)}, C^{(1)} \leqslant s$ $C^{(2)}, B^{(1)} \leqslant_{s} B^{(2)}$ and $A^{(1)} \leqslant_{L} A^{(2)}$, then $\mathbf{T}^{1} \leqslant_{s} \mathbf{T}^{2}$, where $\leqslant_{s}$ is one of the symbols $\leqslant_{s t}$ or $\leqslant_{v}$. I.e. for any distribution $\omega$, we have $\mathbf{T}^{1} \omega \leqslant_{s} \mathbf{T}^{2} \omega$.

Proof. It is well known that to prove $\mathbf{T}^{1} \leqslant_{s} \mathbf{T}^{2}$, we have to show the following numerical inequalities for the one-step transition probabilities $P_{i j}^{(1)}$, $P_{i j}^{(2)}$ (see Stoyan [5]): $\bar{P}_{i j}^{(1)} \leqslant \bar{P}_{i j}^{(2)}, \forall i, j,\left(\right.$ for $\left.\leqslant \leqslant_{s}=\leqslant s t\right)$, and $\overline{\bar{P}}_{i j}^{(1)} \leqslant \overline{\bar{P}}_{i j}^{(2)}, \forall i, j$, (for $\leqslant_{s}=\leqslant_{v}$ ).

After algebraic manipulations, we obtain the result searched.

\section{Bounds for the stationary distribution}

Now, we add the the corresponding stationary distributions of the number of customers in the system $\pi_{n}^{(1)}$ and $\pi_{n}^{(2)}$.

Theorem 3. If $\lambda^{(1)} \leqslant \lambda^{(2)}, q^{(1)} \leqslant q^{(2)}, \alpha^{(1)} \geqslant \alpha^{(2)}, \mu^{(1)} \leqslant \mu^{(2)}, C^{(1)} \leqslant s$ $C^{(2)}, B^{(1)} \leqslant_{s} B^{(2)}$ and $A^{(1)} \leqslant_{L} A^{(2)}$, then $\left\{\pi_{n}^{(1)}\right\} \leqslant_{s}\left\{\pi_{n}^{(2)}\right\}$, where $\leqslant_{s}$ is one of the symbols $\leqslant_{s t}$ or $\leqslant_{v}$.

Proof. Using Theorems 1 and 2 which state that $\mathbf{T}^{i}$ are monotone with respect to the order $\leqslant_{s}$ and $\mathbf{T}^{1} \leqslant_{s} \mathbf{T}^{2}$, we have by induction $\mathbf{T}^{1, n} \omega \leqslant_{s} \mathbf{T}^{2, n} \boldsymbol{\omega}$ for any distribution $\omega$. Taking the limit, we obtain the stated result.

Theorem 4. We consider an $M / G / 1$ queue with general retrial times allowing balking and server subject to breakdowns and repairs. If we have, the service time distribution $B(x)$ and the repair time distribution $C(x)$ are NBUE and the retrial time distribution is of class $\mathcal{L}$, then $\left\{\pi_{n}\right\} \leqslant_{v}\left\{\pi_{n}^{*}\right\}$, where $\left\{\pi_{n}^{*}\right\}$ is the stationary distribution in the Markovian retrial queue with the same parameters.

Proof. Consider an auxiliary Markovian $M / M / 1$ retrial queue allowing balking and server subject to breakdowns and repairs, having the same parameters as the model considered in our study, but with exponentially distributed retrial time $A^{*}(x)$, service time $B^{*}(x)$ and repair time $C^{*}(x)$. We have also, if $B(x)$ and $C(x)$ are $N B U E$ and $A(x)$ is $\mathcal{L}$, then $B(x) \leqslant{ }_{v} B^{*}(x)$, $C(x) \leqslant_{v} C^{*}(x)$ and $A(x) \leqslant_{L} A^{*}(x)$. Therefore, by using Theorem 3 , we deduce the statement of this theorem. 


\section{Conclusions}

In this work, we investigated the monotonicity of the transition operator of the embedded Markov chain with respect to stochastic and convex orderings. In addition, we done comparability conditions of the transition operators of the considered systems, associated with two Markov chains. Further, we obtained comparability conditions for which the stationary distribution in the considered model is bounded by the stationary distribution of the Markovian retrial queue, if the service time and the repair time distributions are NBUE and the retrial time distribution is of class $\mathcal{L}$.

\section{Acknowledgments}

The authors are pleased to thank the anonymous referees and the editor for their valuable comments and suggestions, which improved the content and the presentation of this paper.

\section{References}

[1] J. R. Artalejo and A. Gómez-Corral, Retrial queueing system: A computational approach. Berlin: Springer, Berlin, Heidelberg, 2008, 318 pp.

[2] A. A. Nazarov, S. V. Paul, and O. D. Lizyura, "Two-way communication retrial queue with unreliable server and multiple types of outgoing calls," Discrete and Continuous Models and Applied Computational Science, vol. 28 , no. 1 , pp. 49-61, 2020. DOI: 10.22363/2658-4670-2020-28-149-61.

[3] D. Zirem, M. Boualem, K. Adel-Aissanou, and D. Ä̈ssani, "Analysis of a single server batch arrival unreliable queue with balking and general retrial time," Quality Technology \&3 Quantitative Management, vol. 16, pp. $672-695,2019$. DOI: 10.1080/16843703.2018.1510359.

[4] M. Shaked and J. G. Shanthikumar, Stochastic Orders. New York: Springer-Verlag, 2007, $473 \mathrm{pp}$.

[5] D. Stoyan, Comparison methods for queues and other stochastic models. New York: Wiley, 1983, 217 pp.

[6] L. M. Alem, M. Boualem, and D. Aïssani, "Bounds of the stationary distribution in $M / G / 1$ retrial queue with two-way communication and $n$ types of outgoing calls," Yugoslav Journal of Operations Research, vol. 29, no. 3, pp. 375-391, 2019. DOI: 10.2298/YJOR180715012A.

[7] L. M. Alem, M. Boualem, and D. Aïssani, "Stochastic comparison bounds for an $M_{1}, M_{2} / G_{1}, G_{2} / 1$ retrial queue with two way communication," Hacettepe Journal of Mathematics and Statistics, vol. 48, no. 4, pp. 11851200, 2019. DOI: 10.1572/HJMS . 2018.629.

[8] M. Boualem, "Insensitive bounds for the stationary distribution of a single server retrial queue with server subject to active breakdowns," Advances in Operations Research, vol. 2014, no. 1, pp. 1-12, 2014. DOI: $10.1155 / 2014 / 985453$. 
[9] M. Boualem, A. Bareche, and M. Cherfaoui, "Approximate controllability of stochastic bounds of stationary distribution of an $M / G / 1$ queue with repeated attempts and two-phase service," International Journal of Management Science and Engineering Management, vol. 14, no. 2, pp. 79-85, 2019. DOI: 10.1080/17509653.2018.1488634.

[10] M. Boualem, M. Cherfaoui, and D. Aïssani, "Monotonicity properties for a single server queue with classical retrial policy and service interruptions," Proceedings of the Jangjeon Mathematical Society, vol. 19, no. 2, pp. 225-236, 2016.

[11] M. Boualem, M. Cherfaoui, N. Djellab, and D. Aïssani, "A stochastic version analysis of an $M / G / 1$ retrial queue with Bernoulli schedule," Bulletin of the Iranian Mathematical Society, vol. 43, no. 5, pp. 13771397, 2017.

[12] M. Boualem, M. Cherfaoui, N. Djellab, and D. Aïssani, "Inégalités stochastiques pour le modèle d'attente $M / G / 1 / 1$ avec rappels," French, Afrika Matematika, vol. 28, pp. 851-868, 2017. DOI: 10.1007/s13370017-0492-x.

[13] M. Boualem, N. Djellab, and D. Aïssani, "Stochastic inequalities for $M / G / 1$ retrial queues with vacations and constant retrial policy," Mathematical and Computer Modelling, vol. 50, no. 1-2, pp. 207-212, 2009. DOI: $10.1016 / \mathrm{j} . \mathrm{mcm} .2009 .03 .009$.

[14] M. Boualem, N. Djellab, and D. Ä̈ssani, "Stochastic approximations and monotonicity of a single server feedback retrial queue," Mathematical Problems in Engineering, vol. 2012, 12 pages, 2012. DOI: 10.1155/2012/ 536982.

[15] M. Boualem, N. Djellab, and D. Aïssani, "Stochastic bounds for a single server queue with general retrial times," Bulletin of the Iranian Mathematical Society, vol. 40, no. 1, pp. 183-198, 2014.

[16] X. Wu, P. Brill, M. Hlynka, and J. Wang, "An $M / G / 1$ retrial queue with balking and retrials during service," International Journal of Operational Research, vol. 1, pp. 30-51, 2005. DOI: 10.1504/IJOR.2005.007432.

\section{For citation:}

M. Boualem, Stochastic analysis of a single server unreliable queue with balking and general retrial time, Discrete and Continuous Models and Applied Computational Science 28 (4) (2020) 319-326. DOI: 10.22363/2658-46702020-28-4-319-326.

\section{Information about the authors:}

Mohamed Boualem - Full Professor, Professor of Applied Mathematics at the Department of Technology at the University of Bejaia, Algeria. (e-mail: robertt15dz@yahoo.fr, phone: +213792991121, ORCID: https://orcid.org/https://orcid.org/0000-0001-9414-714X, ResearcherID: A-3176-2019, Scopus Author ID: 26633399700) 
УДК 519.872:519.217

PACS 07.05.Tp, 02.60.Pn, 02.70.Bf

DOI: $10.22363 / 2658-4670-2020-28-4-319-326$

\title{
Стохастический анализ системы типа «клиент-сервер»с ненадёжной очередью с блокировкой и общим временем обновления
}

\author{
Мохамед Буалем \\ Исследовательское подразделение LaMOS \\ Факультет технологий, Университет Беджал, Алжир
}

В статье рассматривается система массового обслуживания типа $M / G / 1$ с обобщённым временем обновления, допускающая блокировку, выход из строя и возобновление работы сервера. Кроме того, клиент, обслуживание которого прервано, может оставаться на сервере в ожидании восстановления его работы, а может покинуть систему и вернуться в период восстановления работы сервера. Серверу не разрешается начинать обслуживание других клиентов до тех пор, пока текущий клиент не завершит обслуживание, даже если он временно отсутствует. Эта модель имеет потенциальное применение в различных областях, таких как сеть когнитивного радио, производственные системы и т. д. Методология строго базируется на общей теории стохастических порядков. В частности, получены оценки стационарного распределения вложенной цепи Маркова рассматриваемой системы.

Ключевые слова: очередь с обновлением, цепь Маркова, блокировка, выход из строя и восстановление, стохастический порядок, границы, классы старения 